This item was submitted to Loughborough's Research Repository by the author.

Items in Figshare are protected by copyright, with all rights reserved, unless otherwise indicated.

\title{
The realignment of offshoring frame disputes (OFD): an ethnographic ‘cultural’ analysis
}

\section{PLEASE CITE THE PUBLISHED VERSION}

http://dx.doi.org/10.1057/ejis.2014.5

\section{PUBLISHER}

Palgrave Macmillan / @ Operational Research Society Ltd.

\section{VERSION}

AM (Accepted Manuscript)

\section{PUBLISHER STATEMENT}

This work is made available according to the conditions of the Creative Commons Attribution-NonCommercialNoDerivatives 4.0 International (CC BY-NC-ND 4.0) licence. Full details of this licence are available at: https://creativecommons.org/licenses/by-nc-nd/4.0/

\section{LICENCE}

CC BY-NC-ND 4.0

\section{REPOSITORY RECORD}

Ravishankar, M.N.. 2017. "The Realignment of Offshoring Frame Disputes (OFD): An Ethnographic 'cultural' Analysis". Loughborough University. https://hdl.handle.net/2134/16920. 


\title{
The realignment of offshoring frame disputes (OFD): An ethnographic 'cultural' analysis
}

\begin{abstract}
In IS research on cross-cultural issues, cultural categories are typically introduced as analytical labels that explain why and how organizational groups in different parts of the world act and think differently. However, broad cultural categories can also be discursively mobilized by organizational members as strategic adaptive resources. Drawing on an ethnographic study of offshoring frame disputes (OFD) in an Indian subsidiary unit of a large Western information technology (IT) organization, this paper explores how members actively invoke a series of beliefs about Western culture and implicitly position them as the binary opposite of Eastern (or Indian) culture. The findings demonstrate how the mobilization of such beliefs eventually plays a vital role in the reconciliation of four different types of OFD. Drawing on the analysis, I build a social-psychological process model that explains how frame extensions trigger a cognitive reorganization process, leading to the accomplishment of OFD realignment. Theoretically, the paper argues that discursively invoked binary cultural categories help maintain non-confrontational definitions of situations and sustain working relationships in IT offshoring environments. Furthermore, interpretations linked to cultural notions seem to reflexively take the offshore-onshore power differentials into account.
\end{abstract}

Keywords: Frame disputes, Ethnography, Offshoring, Culture, India 


\section{Introduction}

In globally distributed IT organizations teams from different countries are often required to collaborate on projects. Despite the presence of clearly established processes to co-ordinate and govern such relationships, disagreements and conflicts often erupt between onshore and offshore teams (see Walsham, 2002; Dibbern et al., 2008; Barrett \& Oborn, 2010). While many disputes are resolved following the admittance of inadvertent error by managers or team members on one side, there also arise a class of disputes where assignment of culpability is much harder. These are what sociologists refer to as 'frame disputes' (Goffman, 1974; Benford \& Snow, 2000). A frame dispute results when “...there is no way in theory to bring everyone involved into the same frame. Under these circumstances, one can expect that the parties with opposing versions of events may openly dispute with each other over how to define what has been or is happening” (Goffman, 1974, pp.322). In effect, each side frames reality in accordance with different schemata of interpretation thus making alignment of conflicting frames an elusive objective for the participants. At stake during frame disputes are meanings of particular situations and events (Benford, 1993; Azad \& Faraj, 2011). Fiction and non-fiction provide a number of illustrative examples. For instance, there is the famous old Indian fable of the six blind men, who are caught up in an almost impossible to reconcile frame dispute because each one of them touch a different part of the elephant and consequently frame the animal's characteristics differently (see Leonardi, 2011).

In order to examine disagreements and disputes between organizational members located in different countries, IS research has for long favoured the application of the culture lens (see Walsham, 2002; Keil et al., 2007). Culture is viewed as an appropriate analytical construct or as a causal variable, which can adequately account for diverse opinions, perspectives and disputes (see Dustdar \& Hofstede, 1999; Avison \& Banks, 2008; Sarker \& Sarker, 2009; Fang et al., 2011; Ravishankar et al., 2011). However, culture is more than just an analytical construct. Notions of culture may also be discursively deployed as a key resource to manage and realign frame disputes (see Barinaga, 2007), an aspect which IS research on culture and cross-cultural differences has largely ignored. This paper explores how organizational members in offshore locations discursively invoke deeply held beliefs about various aspects of Western culture to correct and realign offshoring frame disputes (OFD). In the main, the paper adds to existing IS research on IT offshoring by critically examining how discursive conceptualizations of the idea of culture can play a vital role in 
offshore-onshore collaborative IT work. Grounded in rich ethnographic data, it provides a nuanced alternative to mechanical and simplistic applications of culture and cultural differences in IS research. The paper also develops theoretical insights into the cognitive interpretive work involved in the process of realigning frame disputes.

\section{Frame disputes}

In his masterly work Frame Analysis, the sociologist Erving Goffman (1974) coined the term 'frame dispute' to refer to disagreements that develop between teams when each side operates under the guidance of different frames or schemata of interpretation. In Frame Analysis Goffman provides several witty and thought-provoking examples of frame disputes in social life. For instance, a frame dispute results when activities on Friday night framed by a group of adolescents as 'fun' is however framed by officialdom as 'vandalism' (Goffman, 1974, p.321). Although there are legal resolutions, Goffman's point is that even legal adjudications in such cases rely on particular interpretive framings of propriety. Thus, a particular event or activity can be framed and interpreted differently in accordance with the different organizational realities and mental models of the actors involved (Snow et al., 1986; Benford, 1993; Benford \& Snow, 2000; Leonardi, 2011). Some recent IS research has adopted the notion of frames and provided illustrations of framing misalignments and their organizational consequences. Hsu (2009) examined variations in framings between employees, managers and certification teams during the implementation of an IS security certification process. Another study by Lin and Silva (2005) demonstrated how user groups' framings of technology can be reframed by purposeful intervention. In general, IS research has focused mainly on disputes involving technology framings i.e., the taken-for-granted assumptions, expectations and knowledge surrounding a particular technology, which influence organizational members' thinking and actions towards the technology (see Orlikowski \& Gash, 1994; Davidson, 2006; Azad \& Faraj, 2011; Leonardi, 2011).

Disputes and conflicts that develop more generally in globally distributed organizations, however, go well beyond differences in technology framings (see Hinds et al., 2011). In other words, framing conflicts confronting offshore-onshore collaborative IT work are not linked only to contrasting perspectives of particular technologies. As the empirical sections in this paper show, framing differences could develop in relation to several other dimensions of collaborative work. This suggests that a much broader and general application 
of the idea of frame disputes is particularly relevant in the case of IT offshoring relationships. In order to examine such disputes in greater depth, this paper applies Goffman's conceptualization of a frame dispute to IT offshoring relationships and defines offshoring frame disputes (or OFD) as disputes wherein offshore and onshore organizational members openly frame the same activity, event or situation in mutually competing and contrasting ways. Several features of offshoring relationships - they not only span different national boundaries but also bring together teams from diverse socio-economic, cultural, religious and educational backgrounds - can render them vulnerable to OFD. Obviously, OFD must not be allowed to gather momentum and escalate because they increase mutual tensions and can have a damaging impact on the offshoring relationship. OFD are evidently at play in IT offshoring relationships that appear to fail and collapse even when there are formal processes and detailed and unambiguous contracts (see Jain et al., 2011). In many cases, although they don't breakdown completely, IT offshoring relationships appear to frequently encounter uncertainty, tension and bitterness (see Ravishankar, et al., 2010; Zimmermann and Ravishankar, 2011) as a consequence of framing differences. The onus, therefore, is clearly on offshore and onshore members of the organization to manage the framing differences so that the OFD are reconciled and realigned. Although exploring OFD in detail can help develop both theoretical and practical insights into how offshoring relationships can be better organized and structured, IS research on offshore-onshore relationships seems to have rarely examined incongruent frames and their management. In particular, there is very little empirical work on the ways in which broad cultural categories might be invoked in these settings to effectively manage and realign OFD.

\section{Culture and offshore-onshore relationships}

Research suggests that despite the globalization-induced move towards cultural standardization, cultural differences between onshore and offshore organizational groups persist (Sarker \& Sarker, 2009; Jain et al., 2011). The culture lens now enjoys significant explanatory authority in IS research (see Nicholson \& Sahay, 2001; Veiga et al., 2001; McCoy et al., 2007; Fang et al., 2011). The culture lens demonstrates how the shared values, beliefs, norms and practices of members in a remote offshore location can be significantly different from those onshore, thereby presenting numerous managerial challenges (see Avison \& Banks, 2008). For example, in a study of projects offshored to India, Dibbern et al. (2008) found that Indian offshore professionals belonged to a highly conformist and 
hierarchical culture unlike their German counterparts. These cultural characteristics of the Indian side increased the effort the German side had to put into writing software specifications and transferring knowledge to the offshore unit. Similarly Sarker and Sarker (2009) suggest that developing inter-cultural competences and overcoming the barriers created by cultural differences are a key part of achieving strategic agility in globally distributed IS development projects. More recently, Jain et al. (2011) have pointed out that cultural adaptation is vital to mitigating the tendency of offshore vendors to remain silent and to not provide an accurate report on the status of projects. While agreeing in principle with its immense analytical value, some IS scholars have rightly criticized homogeneous representations of cross-cultural differences and called for a more nuanced application of the culture lens (e.g., Walsham, 2002). Ravishankar et al. (2011) point out that it is important to consider the impact of contradictions and conflicting patterns that exist within what is otherwise seen as a culturally homogeneous offshore entity. Overall, the application of the culture lens illuminates the potential of cross-cultural differences and cultural diversity to influence disputes between and within globally distributed teams. However, in this paper, as a point of departure from earlier work I intend to advance the argument that the role of culture is not limited to its application as a lens.

\section{Culture as a Resource and Frame disputes}

Viewing culture only as an enduring conceptual tool can be quite restricting since it is built on the narrow premises that culture's existence precedes the actions of group members and that it exists independently of the groups whose characteristics it supposedly describes (Walsham, 2002; Barinaga, 2007; Leonardi, 2011). An alternative and broader perspective grounded in the ethnomethodological traditions focuses on exploring how notions of culture and cross-cultural differences are actually invoked by globally distributed groups to achieve certain strategic purposes (Cohen \& El-Sawad, 2007). In the latter sense, claims made by organizational members about culture can therefore be also seen as an available discursive resource that can be drawn upon both to make sense of and to solve everyday issues in collaborative work environments. Here, the term 'discursive resource' is used in line with Foucault's notion of a discourse, which is best captured in Tony Watson's words (1994, p.114): "a connected set of statements, concepts, terms and expressions, which constitute a way of talking and writing about a particular issue, thus framing the way people understand and act with respect to the issue.” In the particular case of culture, as Barinaga (2007, pp.319) 
notes, "the relevance of culture lies not in it being conformed to in action, but in it being taken into account as an available resource for making sense of action”. Put differently, 'cultural differences' are not merely a particular manifestation of cognitively constraining variations in values and beliefs, as cross-cultural IS research suggests, but are also a valuable resource into which 'people impute variable and fluctuating meanings' (Ailan-Souday \& Kunda, 2003, pp. 1075). The bigger question to ask of course is what specific purposes do the mobilization of culture as a discursive resource serve? Research suggests three broad categories of purposes. Firstly, culture and associated concepts can be used as symbolic resources to serve social struggles. For instance, in an ethnographic study of a merger between an Israeli and American high-tech firm, Aidan-Souday \& Kunda (2003) showed how Israeli informants used the idea of national culture and identity as a boundary-spanning symbol of detachment from the proposed merger. In research on collaborative IT teams, Walsham (2002) and Barrett and Oborn (2010) have provided some rich data about how Jamaican software developers used cultural arguments to resist the working style of Indian expatriate managers.

Secondly, notions about culture are frequently deployed to serve larger political agendas of special interest groups (Frenkel, 2008). For example, to protect onshore jobs that could otherwise be profitably moved offshore, managers can introduce exaggerated ideas about the cultural idiosyncrasies of offshore members (Zimmermann \& Ravishankar, 2011). Thirdly, cultural explanations can be used by organizational members as resources to work around the many difficult and tricky every day processes of globally distributed work (Cohen \& El-Sawad, 2007). It is this third category of deployment of culture as a discursive resource that this paper engages with. Cultural explanations that members draw on can help them in negotiating frame disputes, which arise frequently in international work contexts. In the organization studies literature, Barinaga (2007) describes how a multi-country workgroup of academic scholars handled awkward situations, defused conflicts and overcame disagreements during a collaborative project. Although she does not explicitly use the term frame disputes, it is evident that due to their different educational backgrounds and personal expectations her respondents framed their proposed collaborative project very differently from one another. With different frames of reference, they infused the project with contradictory meanings leading to frame disputes. In her paper, Barinaga (2007) also vividly demonstrates how ideas of 'cultural diversity' and 'national culture' were discursively deployed by her respondents to realign the frame disputes that they were caught up in. I 
extend this line of thought further in this paper to globally distributed organizations and explore how culture might be used as a discursive resource to navigate through and reconcile OFD.

In summary, the functioning of globally distributed IT organizations involves complex trans-national relationships, which suggest a series of salient and active frame disputes. OFD refer to frame disputes involving the contrasting framing of events by offshore and onshore organizational members. While the notion of culture has been applied usefully as a suitable lens to explain various dimensions of IT offshoring, there is little research on how cultural explanations can be deployed discursively as a resource by organizational members to manage and realign OFD. In the sections below, I develop these arguments through an ethnographic study of an Indian offshore subsidiary of a large global IT organization.

\section{Methods}

I developed the core ideas of this paper through a six month long ethnographic study. Ethnographic approaches have their roots in anthropology and are characterized by the researcher's immersion in the everyday life of the observed (Van Maanen, 1979; Mattarelli et al., 2013; Watson, 2011). Ethnographers spend extended periods of time in the field and collect vast amounts of empirical material through unstructured interviews and observations (Atkinson \& Hammersley, 2007). Ethnographic studies are particularly helpful in developing a deeper understanding of the everyday processes through which organizational members construct and develop their social worlds. In this study, rather than applying culture as a lens to investigate differences in values, beliefs and norms between onshore and offshore members, I have explored organizational members' discursive use of culture as a resource. Thus from a more expansive methodological standpoint, this study follows the traditions of ethnomethodological inquiry, which makes a fundamental distinction between social ideas as topics and their utilization as a resource (Watson, 2002; Sharrock \& Randall, 2004). Ethnomethodology argues against over-using sociological descriptions (e.g., 'professions', 'bureaucracy' etc.) to analyze work settings and suggests that researchers must instead explore how organizational members make use of such descriptions to comprehend the world they live in (Watson, 2002). In other words, ethnomethodology brings sociological descriptions from their structural position behind the actor and sets them in front, as ideas of which the actor is fully aware (Barinaga 2007, pp.319). In this ethnographic study, I have 
approached the notion of culture, in particular the notion of Western culture, as an ethnomethodological concept of interest. Although I have presented the paper using the conventional linear structure in order to assist readability and comprehension, the process of developing the paper was inevitably circular, as is the case with most ethnographic work. Much of the ideas in this paper about the discursive use of culture and OFD were developed iteratively, travelling back and forth from the fieldwork data to the literature.

\section{Research site}

SUB and HQ are the Indian subsidiary and the European headquarters respectively of a large Western IT organization. Throughout the paper, I use the phrase 'SUB members' to refer to employees of the Indian subsidiary and the phrase 'HQ members' to refer to employees of the European headquarters. SUB, the Indian subsidiary was set up more than ten years ago as part of an offshoring strategy of the larger global IT organization. It now comprises more than 20,000 members who are organized into five strategic business units, within which are a number of project teams. Most of the SUB project teams have a HQ counterpart. That is, members of the respective HQ and SUB teams collaborate on a series of software development projects, which serve global clients across a range of industries and sectors such as automobile, retail, insurance and banking. Collaborative activities of the SUB and HQ members span most of the areas of a typical software development cycle including requirements gathering, design, coding, documentation, testing and the on-going maintenance of the delivered system. This collaboration is facilitated and supported through frequent video-conferencing, e-mail interaction and telephonic conversations. Like in many other IT offshoring relationships, some SUB members make periodic short visits to HQ (and viceversa) to improve cross-cultural understanding and to oversee important phases of projects. SUB members are typically graduates in computer science or electronics engineering and are recruited from top-ranking engineering programs in India. Many middle-level and senior managers also possess MBA degrees from reputed Indian, American and European business schools. SUB teams are located in most of the major Indian cities. I conducted fieldwork in three Indian cities, which house three of the largest SUB software development centers in India.

\section{Fieldwork}

Over a six month period, I used a range of fieldwork techniques to collect data. Given the micro-level focus on the management of OFD in the offshore unit, the primary data for 
this paper was generated solely from SUB informants. In other words, it is the offshore informants' perspective of the OFD, which is explored and analyzed throughout this paper. I observed a number of activities such as cross-cultural training programmes, strategy meetings of SUB project teams and SUB members' conference calls with HQ members. These observations led to the generation of more than 500 pages of field notes. Fortunately, in each of the three SUB locations I was given a room to work, with access to SUB members' workspaces. Thus, I was able to have a number of informal conversations everyday with SUB members from different levels of the organizational hierarchy. 'Hanging out' in the ubiquitous cafeteria also led to many fruitful interactions. At the end of each day of fieldwork, I made extensive notes about the informal conversations I had engaged in during that day. Empirical data was also generated using interviews with SUB members. I conducted open-ended interviews with 61 SUB members (see Table 1). Most of the interviews were digitally recorded and transcribed. I made manual notes when informants did not consent to the audio recording. Informants included entry-level software engineers, senior software engineers, project leaders, HR managers, project managers, business unit heads and seniorvice presidents. On average, informants had worked at SUB for about three and a half years. Some of the more senior informants had been at SUB for close to ten years. A few informants had joined SUB only recently, but had prior experience of working in the IT offshoring sector and interacting with Western clients.

The interviews began with a general question about SUB members' relationship with HQ members, which was followed by a free-flowing discussion about why and how SUB members managed to work effectively (or not) with their onshore collaborating team. The interviewees spoke freely and candidly about the challenges and problems they faced in the process of collaborating with HQ. Many interviewees had to be frequently reassured during the interviews that I would not name them in any report that I might produce at the end of my fieldwork. Members from project teams in all the five SUB business units were represented in the interviews.

\begin{tabular}{|c|c|}
\hline $\begin{array}{c}\text { Informant category } \\
\text { (Business units BU1, BU2, BU3, BU4, BU5) }\end{array}$ & Number of Informants \\
\hline Software engineers & 19 \\
(BU1: 4, BU2: 2; BU3: 4, BU4: 4, BU5: 5) & \\
\hline
\end{tabular}




\begin{tabular}{|c|c|}
\hline $\begin{array}{c}\text { Project leaders } \\
\text { (BU1: 3, BU2: 3; BU3: 2, BU4: 4, BU5: 3) }\end{array}$ & 15 \\
\hline Human resource (HR) managers & 3 \\
\hline $\begin{array}{c}\text { Project managers } \\
\text { (BU1: 5, BU2: 2; BU3: 2, BU4: 5, BU5: 4) }\end{array}$ & 3 \\
\hline $\begin{array}{c}\text { Business-unit heads } \\
\text { (BU1, BU3 and BU4) }\end{array}$ & 3 \\
\hline $\begin{array}{c}\text { Senior Vice-presidents } \\
\text { (BU1, BU2 and BU5) }\end{array}$ & $\mathbf{6 1}$ \\
\hline Total & \\
\hline
\end{tabular}

Table 1. An overview of the open-ended interviews

\section{Data analysis}

I scrutinized the notes from the observations, the informal conversations and the interviews line by line to identify recurrent themes. Through this process, I identified four themes relating to aspects of collaborative work where SUB members felt they had important differences with HQ members. Following Van Maanen (1979) and Pratt (2006), I coded these themes into four second-order interpretive concepts: tasks-related, outcome-related, organizational boundary-related and commitment-related disputes. I created separate word documents on the computer for each of these interpretive concepts. In these four documents I wrote down a detailed narrative summary of the origins of each dispute and the coping strategies of the SUB members in relation to these disputes. At this stage, I drew on an extensive review of the sociology literature in an attempt to create a theoretically grounded description, which could explain the fundamental structure of the disputes. Goffman's (1974) notion of frame disputes aligned closely with the kind of differences at play in the SUB-HQ relationship. Given their embeddedness in the offshoring context, I created the category of offshoring frame disputes (OFD). I then had long discussions over the phone with several of my key contacts at SUB to explain my initial formulations and to ascertain the accuracy and validity of my preliminary analysis. By this time, it was evident that the summaries corresponding to each of the disputes had frequent references to the cultural differences between the West and the East. I then adopted a 'selective' scheme (Strauss \& Corbin, 1998) to identify the cross-cultural themes, which SUB members often cited in relation to their management of each of the OFD. These themes were apparent at two levels - first, at the 
macro-level of the perceived characteristics of Western culture and second, at the more micro-level of how such characteristics fed into the SUB's relationship with HQ. I then iteratively moved back and forth from these thematic formulations to the literature on frame analysis. This process led to the inductive development of a social-psychological model of OFD realignment, which was supported both by the ethnographic data and by the theory on frame realignment.

\section{Analysis}

The empirical material clearly showed how OFD were ubiquitous in the SUB's relationship with HQ. Interestingly, these OFD did not seem to be the result of any blatant violation of rules, protocols and procedures by the SUB members. They existed despite the SUB members appearing to closely follow all the guidelines and processes governing the offshoring relationship. Four types of OFD were prominent, whose careful management was essential in order to ensure a harmonious relationship between SUB and HQ members. In order to make sense of the OFD and to reconcile them, SUB members frequently drew discursively on their beliefs about Western culture. Many SUB members conflated the notion of Eastern culture with the notion of Asian and Indian cultures. Below, I present an analysis of the results of the ethnographic fieldwork, which is organized around SUB members' experiences of the four different types of OFD. This analysis is then followed by a detailed discussion section.

\section{Tasks-related OFD}

As with many onshore-offshore relationships, well-defined processes were in place to organize the sharing and implementation of tasks between HQ and SUB teams. Yet SUB members argued that disagreements were frequent. A project leader explained:

"Collaborating with HQ is not easy. There are times when the specifications we get from the HQ team are just not clear. But when we ask them, they simply refuse to clarify. What is even more irritating is that the whole thing is branded as 'poor ability of offshore personnel'".

The complaint of many members was that reasonable requests for clarification or assistance made to the HQ members were interpreted as signs of incompetence of the entire SUB unit. In the words of a software engineer: 
"There was this one time when I requested this dude onshore for help because I could not understand his codes and I needed to understand the logic he had used. He just went ballistic in his e-mail accusing me of being poorly trained and incompetent. They always escalate such things to show us in a poor light. I mean, I am just asking for a small help.”

In a larger sense, these skirmishes can be termed as tasks-related OFD. Essentially at issue were the contrasting framings on the two sides. While the basic fact was clear to both sides viz., SUB members routinely asked questions and clarifications about specific tasks - the framing was evidently different. From the perspective of the SUB members, it was all about how perfectly legitimate requests for help were being turned down by HQ members. But as a project manager explained, HQ framed it very differently:

"I mean they see things differently. When projects are on in full swing, it is natural for our teams to ask for help from onsite. But they can be very touchy about it. They invariably tend to see it as our guys' inability to work independently".

To explain this contrasting framing, SUB members brought in arguments about what they believed to be the fundamental nature of Western culture. These arguments were best illustrated by a project manager who pointed to the differences between Western individualism and Eastern collectivism as a main reason for this OFD:

"This is an ongoing problem. If you do a root-cause analysis, you will see that at the end of the day, Western culture is quite individualistic unlike our collectivistic culture. Each man is an island kind of situation over there. So while we unthinkingly ask each other for help here, it is frowned upon in the West."

Many senior managers suggested that an awareness of how Western individualism is played out had helped them to cope with such disputes. The interesting point here is not so much about individualistic HQ values impacting HQ-SUB relations, as it is about SUB members actively using this notion of the individualistic West to make sense of disputes. As a project manager described it:

"We understood this. It takes time for the newer guys to figure it out. But once we figured out that culturally they are different, it became a lot easier to understand why they refused to entertain a lot of questions from SUB. I still think it is amazing that they are so individualistic, but that understanding helps us manage these sensitive areas better." 


\section{Outcomes-related OFD}

The second type of OFD related to the outcomes of projects, in particular to how SUB and HQ members framed instances of delays in delivering project outcomes. A SUB project manager explained:

"With deadlines, there can be slippages. They give me sleepless nights. Not only because we are about to miss a deadline. But, more so because the post-mortem will revolve around the supposed lack of transparency on our side. I know from experience that a deadline missed means we are not transparent (according to HQ)."

On the other hand, for SUB members the fact that a deadline was missed pointed to communication failures on the HQ side. An illustrative quote from a project manager:

"Delivery dates are postponed for many reasons. This may surprise you because of all the stereotypes about poor Indian communicators, but during conference calls, you get people onshore who just speak so fast and use various slangs, which we find hard to interpret. So sometimes, it does not get minuted in the records. This is a major cause of missed deadlines. Poor communication from onsite teams."

A senior software engineer defended the SUB framing of the issue as a communication related problem:

"You get some really poor communicators, who however like to hear their own voice. To add to this, sometimes we are forced to have conference calls at god-forsaken hours and people may not be very alert at such times. I know mistakes happen during projects and sometimes it is clear it happens because of us. But when there is a dispute that is difficult to resolve because no one is taking responsibility, we need to look at communication from the onshore team. Mind you, I am not saying all of us are great communicators, but there is more to it."

As with tasks-related OFD, SUB members quickly turned to notions of culture to justify their own points of view and to also explain why the HQ framing was different. To many SUB members the core issue here was Western cultural attitudes towards relationships and money:

"At the heart of it all, is a certain instrumentality about the way Western culture looks at relationships. The East has a lot to learn from them no doubt, but this is one thing we should not! This instrumentality leads them to be extremely direct in their communication, which is a disorienting experience for many of us. We can't be as direct in saying 'no I can't do it'. We 
try to be as helpful and accommodating. That is Indian culture. Many deadline slippages in onshore-offshore teams happen because of this Western directness” (project leader).

and

"This actually comes up quite a bit in our inter-cultural training programs. I made the point that Western culture is all about time and money. I don't mean it in a negative way. It is just that this explains their directness and we have to learn to cope with it. We cannot afford to destroy the relationship just because we are different cultures. And frankly, they are the HQ and they call the shots. So we can't just get into arguments as and when we feel like" (senior vice-president).

\section{Organizational boundary-related OFD}

HQ and SUB are two integral parts of the same larger Western IT organization. But HQ members often suggested to SUB members that they were only an Indian vendor and that if SUB did not perform its role effectively, HQ would be forced to consider an alternative third-party offshore collaborator. This was the cause of much frustration and anxiety among SUB members because they saw it as a deliberate refusal on HQ's part to acknowledge SUB's right to a shared organizational identity. A senior project manager argued:

"What is the boundary of our organization? We are a global organization, so technically we are as important as HQ. But you know the reality? They often make unreasonable demands and say they will chose an alternative vendor if we don't give in. They actually use the word 'vendor' in formal communications."

Informants pointed out that many HQ teams simply saw themselves as collaborating with an offshore vendor in a competitive global IT market and therefore felt perfectly entitled to demand high quality work at 'arms' length' from SUB. This HQ perspective was just the opposite of how SUB members framed the relationship: SUB members saw themselves as same-status partners in a collaborative relationship with a different unit of the larger organization. To SUB members, the HQ position represented an explicit attempt to deny SUB its rightful status:

"This is a very contentious and troubling issue. When things don't go well, they say you are only a vendor. But we see ourselves as collaborative partners, not as vendors." (senior software engineer). 
Many SUB members argued that in order to comprehend why and how boundary-related OFD develop it was important to first recognize an obvious but unstated fact about Western culture. They suggested that despite the façade of rhetoric about collaboration and teamwork, it was clear that Western culture was intolerant in many respects.

"The truth is this is a kind of intolerance. It is not a very dangerous kind of intolerance which will kill us. But it is a cultural thing. When we see this kind of bitterness, so much so that they refuse to even see us as colleagues, it gives us an insight into how Western culture is intolerant of Indian culture. We can't run away from this fact. That is life."

Some SUB members linked these boundary-related OFD to the diminishing relevance of the West in the global business environment and to the corresponding ascendance of the East. They pointed out that the West's 'consumerist' culture was becoming unsustainable and that the West was now feeling seriously threatened:

“...they are on their way down and they know that. So they are very afraid and they just take it out on us by saying 'you are only a vendor and so on'. I mean offshoring is only going to increase and those HQ members doing routine tasks may lose their jobs soon. So it is just an instinctive reaction to the knowledge that the West as a whole is on its way down.”

Here again, the point is not so much about assessing the extent to which HQ members were actually intolerant or feeling threatened, although these are no doubt relevant issues. But rather, it is about the injecting of cultural meanings into the boundary-related OFD, which emphasizes the important value of calling forth ideas about the so called characteristics of Western culture to make sense of everyday disagreements in offshoring relationships. Most SUB members claimed that although they were agitated initially and harboured ill-feelings against HQ for treating them as a 'low-status' vendor, with time they better understood both the cultural intolerance of the West as well as the 'desperate situation' the West currently found itself in, which they believed had ignited HQ members' resentment.

\section{Commitment-related OFD}

Somewhat paradoxically, in relation to a different type of OFD, members drew a positive picture of Western culture, praising its impressive 'socialist' ideals and highlighting its commitment to citizens. High-attrition rates in SUB gave rise to a kind of framing dispute, which can be termed 'commitment related OFD'. HQ managers were very concerned about attrition since it could mean disrupted projects and excessive time spent on training new 
members. They regularly questioned their SUB counterparts about it, interpreting and framing attrition as an issue of poor organizational commitment. They were aghast that attrition levels were as high as $45 \%$ at times. A senior vice-president at SUB explained:

"Their view is that offshore employees show poor commitment to the organization. I don't see it that way even though I am in a senior position and should be worried about it. To me it is all about these young people focusing on career growth opportunities"

A software engineer exclaimed:

"What's it got to do with commitment? I have to think of my future career and improve my earning potential!”

Overall, SUB members believed that the issue in question had little to do with organizational commitment. Instead, it was about how to find 'career growth opportunities' and 'secure their future' in the intensely competitive, but at the same time financially lucrative IT offshoring sector. They felt that certain core aspects of Western culture underpinned the inherently different framings about attrition. In the words of a senior software engineer:

"We are basically coming at it from different angles. They see it as commitment issues. We don't see it that way. The reason they see it that way is because Western culture is essentially very socialist and takes good care of its citizens. Asian culture is cut-throat. They have all these social security programs. So, people get into a cushy job and think this is a job for life. You get people over there saying 'let me specialize only in one domain'. Naturally, they think we are uncommitted and confused. But remember, even if they screw up their government will help them in some way. Or they can say something like 'let me travel around the world for a couple of years'. They can afford to do it. Their culture is to take care of everyone. The reality for us is very different."

Clearly, SUB members' arguments here about Western culture contradicted their own representations of Western culture as individualistic and instrumental in relation to the tasksrelated and outcomes-related OFD described earlier. Many informants who were quite convinced about Western culture's highly individualistic orientation appeared equally certain about the socialist dimension of Western culture. More importantly, they did not appear too flustered or embarrassed by the thought that they were guilty of holding two almost diametrically opposite views of Western culture. Thus, in the context of the OFD members appeared to extensively play with the idea of Western culture, not concerning themselves too 
much with the need to maintain a consistent intellectual standpoint. When it was pointed out that she was contradicting herself, a project manager argued:

"Well, there is no doubt that Western culture is highly individualistic. But its socialist side also rears its head every now and then."

\section{Discussion}

The above analysis shows how offshore groups discursively draw on the broad notion of 'Western culture' in order to make sense of and to manage a range of OFD. It also suggests that within globalized organizations, actors access and deploy many cultural discourses to negotiate framing disputes in everyday work processes. The arguments about Western culture that SUB members came up with clearly served two important strategic objectives. First, they allowed SUB members to mount a vigorous defense of their own framings of the different types of disputes. Second, by bringing 'culture' into the equation, SUB members were able to use relatively neutral sounding and broad labels to rationalize the HQ members' patently contrasting framing of situations. As a project manager put it: “Quite often we find that their mental frames of reference are not in sync with us. But you have to see that there is a history of cultural differences, which probably explains why we don't see eye-to-eye." In this quote, 'history of cultural differences' is clearly a convenient label which serves the important objective of linking framing differences to events of the past, and thus allows for a more generous evaluation of the role of the HQ members in the disputes than perhaps possible through a rational de-construction. While the SUB members' original projections of the disputes were clearly confrontational and appeared to blame HQ members directly, these latter cultural framings were less judgmental.

Laying the blame at the door of the more abstract notion of 'Western culture' turned SUB members' collective attention away from the perceived negative attributes of HQ members and made it possible to readjust in a respectable and conciliatory manner. This strategic dimension to the SUB members' use of the 'culture' discourse also suggests that equations of power are fully embedded in the discursive use of ideas about Western culture (see Metiu, 2006). Evidently, HQ enjoyed a higher status and it was therefore clearly in the interest of SUB members to not antagonise HQ members. From the SUB perspective, it was therefore imperative that the various OFD had to be negotiated and managed carefully without causing offence to HQ. When using culture as a lens alone, scholars might tend to see 
such attitudes of offshore teams purely in cultural terms. (e.g., 'in Eastern cultures people are polite and don't like to offend' or 'Eastern cultures are very hierarchical' etc.), while ignoring the possibility that cultural discourses serve strategic purposes and may be linked to unequal power relations (see Avison \& Banks, 2008; Jain et al., 2011). The deft applications of 'cultural' arguments may also provide one good explanation for the tremendous resilience of many offshore-onshore relationships, even when there are a range of OFD in play. As long as members have access to a toolkit of discursive explanations about the 'other' culture, they can seemingly adapt to ensure that the different types of OFD are managed and reconciled.

\section{A social-psychological process model of OFD realignment}

The sociology literature has suggested that realignment of frame disputes takes place through the micro mobilization of a series of social-psychological mechanisms (Snow et al., 1986; Benford \& Snow, 2000). In particular, Snow et al.’s (1986) conceptualization of the 'frame extension' mechanism is of special relevance here since it can help us synthesize the analysis above into a social-psychological process model of OFD realignment. In the main, 'frame extension' suggests that actors frequently extend the boundaries of their initial cognitive framework by invoking aggregate-level issues and beliefs. These frame extensions help them inject new meaning into disputed events and situations. Extending or widening the boundaries of the initial frame through the injection of various cultural material can function to eventually reorganize experience and realign frame disputes.

\begin{tabular}{|l|l|l|l|l|}
\hline Type of OFD & $\begin{array}{l}\text { Frame 1: The } \\
\text { HQ framing }\end{array}$ & $\begin{array}{l}\text { Frame 2: The } \\
\text { SUB framing }\end{array}$ & $\begin{array}{l}\text { Beliefs about } \\
\text { Western } \\
\text { culture which } \\
\text { extend the SUB } \\
\text { framing }\end{array}$ & $\begin{array}{l}\text { Subjective } \\
\text { interpretations } \\
\text { in the extended } \\
\text { frame }\end{array}$ \\
\hline Tasks-Related & $\begin{array}{l}\text { SUB cannot } \\
\text { handle tasks } \\
\text { independently. }\end{array}$ & $\begin{array}{l}\text { HQ members } \\
\text { frequently turn } \\
\text { down legitimate } \\
\text { requests for } \\
\text { assistance. }\end{array}$ & $\begin{array}{l}\text { Western } \\
\text { individualism. }\end{array}$ & $\begin{array}{l}\text { HQ teams try to } \\
\text { limit interaction } \\
\text { because they are } \\
\text { individualistic. }\end{array}$ \\
\hline $\begin{array}{l}\text { Outcomes- } \\
\text { related }\end{array}$ & $\begin{array}{l}\text { SUB suffers } \\
\text { from a lack of } \\
\text { transparency. }\end{array}$ & $\begin{array}{l}\text { Deadlines are } \\
\text { missed because } \\
\text { HQ members } \\
\text { are poor } \\
\text { communicators. }\end{array}$ & $\begin{array}{l}\text { Instrumentality, } \\
\text { directness and } \\
\text { materialism of } \\
\text { Western culture. }\end{array}$ & $\begin{array}{l}\text { HQ members } \\
\text { are highly } \\
\text { focused on } \\
\text { monetary } \\
\text { benefits and } \\
\text { gains. }\end{array}$ \\
\hline $\begin{array}{l}\text { Organizational } \\
\text { boundary- }\end{array}$ & $\begin{array}{l}\text { SUB members } \\
\text { are only }\end{array}$ & $\begin{array}{l}\text { SUB members } \\
\text { are same-status }\end{array}$ & $\begin{array}{l}\text { Western culture } \\
\text { is intolerant and }\end{array}$ & $\begin{array}{l}\text { HQ members } \\
\text { are seriously }\end{array}$ \\
\hline
\end{tabular}




\begin{tabular}{|l|l|l|l|l|}
\hline related & $\begin{array}{l}\text { offshore } \\
\text { vendors. }\end{array}$ & $\begin{array}{l}\text { partners in a } \\
\text { collaborative } \\
\text { relationship. }\end{array}$ & $\begin{array}{l}\text { threatened by } \\
\text { the rapid growth } \\
\text { of the East. }\end{array}$ & $\begin{array}{l}\text { worried about } \\
\text { losing jobs. }\end{array}$ \\
\hline $\begin{array}{l}\text { Commitment- } \\
\text { related }\end{array}$ & $\begin{array}{l}\text { SUB members } \\
\text { show poor } \\
\text { commitment to } \\
\text { the } \\
\text { organization. }\end{array}$ & $\begin{array}{l}\text { It is necessary to } \\
\text { focus on career } \\
\text { growth } \\
\text { opportunities. }\end{array}$ & $\begin{array}{l}\text { Western culture } \\
\text { is essentially } \\
\text { socialist and } \\
\text { takes good care } \\
\text { of its citizens. }\end{array}$ & $\begin{array}{l}\text { HQ members } \\
\text { benefit hugely } \\
\text { from state } \\
\text { support. }\end{array}$ \\
\hline
\end{tabular}

Table 2. OFD, Beliefs about Western culture and their reinterpretations

SUB members extended their initial framings of the OFD by discursively mobilizing several beliefs about Western culture (see Table 2). In explaining tasks-related OFD, they positioned Western individualism as the binary opposite of Eastern collectivism. In the case of outcomes-related OFD, they invoked the 'instrumentality', 'directness' and 'materialism' of Western culture. When organizational boundary-related OFD arose, they summoned up the idea of a Western culture that was intolerant and feeling threatened by a fast emerging East. Finally, when their commitment to the organization was questioned, they pointed to the essentially socialist nature of Western culture as an important factor in the dispute. These discursively created beliefs about the apparent characteristics of Western culture helped cognitively incorporate the OFD in an extended framework of cultural explanations.

However, theory suggests that locating the OFD in an expanded and extended cultural framework does not directly secure realignment. A further stage of psychological reinterpretation is often required. As Goffman points out (1974, p.340), although teams may provide themselves with various sources of socially constructed evidence (about Western culture, in the case of SUB members), such evidence must be fully applied mentally 'to provide a subjective, cognitive reorganization' before a frame dispute is realigned. It is evident that SUB members applied the material available in their extended 'cultural' frame, to provide themselves with a cognitively reprocessed and highly subjective interpretations of the likely causes of OFD (see Column 5 in Table 2). Ideas about Western individualism were reinterpreted locally to arrive at a new understanding viz., since HQ members are individualistic, they try to limit interaction with SUB members. Similarly, the idea of an instrumental Western culture was applied to HQ to argue that HQ members were always focused on financial gains and benefits. To SUB members, these new interpretations 
seemingly gave a rational and convincing explanation for the presence of OFD. They felt that they could now clearly comprehend why HQ members adopted the stances they did. This almost respectful acknowledgment and consideration for HQ’s cultural orientations, a notion which in fact they invoked discursively, helped SUB members to psychologically come to terms with the contrasting framings. In this sense, realignment of frame disputes occur when discursive beliefs extend the initial frame, providing a vast repertoire of cultural material (see Chreim, 2006). Members' engagement with this material then triggers a cognitive reorganization process of new subjective local interpretations. These new interpretations help members mentally reconcile the inevitable tensions of working with competing frames, thus achieving realignment of the OFD. This process is depicted in the model below (see Figure 1). OFD realignment can therefore be defined as the collective mental reconciliation of OFD which protects the offshoring relationship from further conflict and thus ensures its continuity.

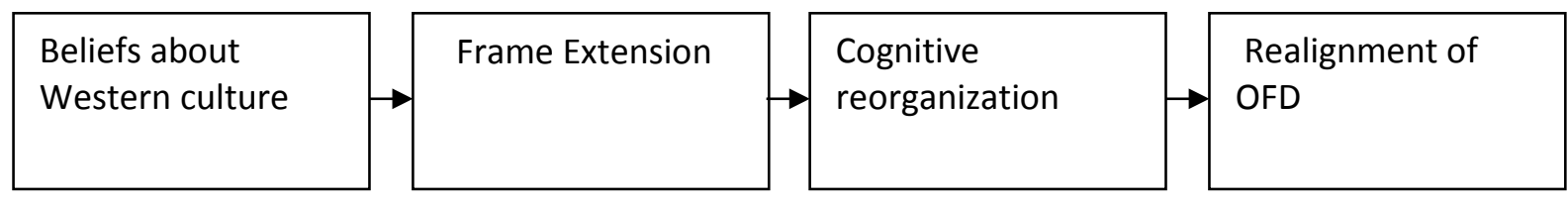

Figure 1. A social-psychological process model of OFD realignment

It is important to note that the cultural interpretations (see Columns 4 and 5 in Table 2) have a certain common-sensical quality to them. They are typical of the cultural interpretations that we might frequently encounter in the Indian popular media (e.g., blogs, newspaper articles, TV shows etc.) and business press about onshore employees. Hence, it would seem that these arguments are very effective in realigning OFD precisely because it is almost natural to invoke and interpret the actions of Western counterparts in such a manner. Consequently, it is debatable whether any unfamiliar or culturally alien types of interpretations will ever lead to OFD realignment.

Although the model above elucidates the key micro-cognitive processes of accomplishing OFD realignment, it is also necessary to recognize the influence of broader forces at play. I have suggested earlier that one of the reasons why the SUB members' new subjective interpretations triggered realignment and not further conflict can be found in the relatively high status enjoyed by HQ. As a senior vice-president put it “... they are the HQ and they call the shots. So we can't just get into arguments as and when we feel like." In this 
sense, OFD realignment is invariably precarious and contingent upon shifts in the broader asymmetries of power and status that govern the HQ-SUB relationship (see Metiu, 2006). This suggests that even when they summon up similar cultural discourses about Western culture, SUB members may be far less inclined to realign the OFD through conciliatory 'cultural' explanations if they happened to enjoy a higher status in the relationship. When status differences between onshore and offshore teams reduce over time, cultural discourses can slowly lose their currency. We may then expect offshore teams to resolve OFD by adopting more direct approaches (e.g., free and open exchange of views) in their interactions with onshore teams. One puzzling aspect of the data worth reflecting upon is how SUB members viewed Western culture as individualistic in relation to one type of OFD and used the somewhat counter-intuitive sounding label 'socialist' to describe Western culture in relation to another type of OFD. While it is hard to fully resolve this apparent contradiction in terms, a tentative, albeit slightly speculative explanation could be offered. The SUB informants in this study collaborated only with their Western European, but not with their US counterparts. They may have been influenced by the popular belief that the US is far more individualistic than Western Europe, which is generally seen as individualistic, but at the same time also rooted in a long tradition of socialism (see Hayek, 1944; Lipset, 1996; Lane, 2000).

There is another useful way to think about the process model described in Figure 1 above. Consider the consequences of this social-psychological process of achieving OFD realignment being played out over and over again during collaborative engagements with the onshore unit. As 'cultural' explanations gain ground and are viewed as a safe and legitimate approach to managing OFD, they could very well become institutionalized in the SUB environment. In other words, the invoking of 'cultural' arguments may become an integral part of SUB members' shared tacit assumptions and beliefs about how to avoid disputes and conflicts with the Western HQ. Within the SUB environment these assumptions can 'drop out of awareness' (Schein, 2009) and over time come to be taken for granted as the right way to think. Thus, the repetitive adoption of 'cultural' arguments to realign OFD could lead to the emergence and development of a particular kind of culture at the SUB level characterized by very rigid, dogmatic and stereotypical ways of viewing the Western HQ. In the empirical data section presented earlier there are clearly several illustrations of such a cultural orientation. We may therefore bring in the notion of 'culture as a lens' into our analysis and argue that the organizational culture prevailing at the SUB level also plays a part in the creation and 
management of the OFD. Indeed, the social-psychological process of realigning OFD is not orchestrated in a vacuum. Particular frame extensions/interpretations are also a reflection and a manifestation of the broader organizational culture at the SUB level. Thus, the process model also provides some insights into elements of the offshore unit's organizational culture. Accounting for culture, in this manner, as a variable, of course does not invalidate the process model developed in the paper. Rather, it adds to our understanding of the complex ways in which culture, both in its substantive as well as discursive forms affect offshore-onshore collaborative projects.

\section{Theoretical implications}

The research approach suggested in this paper theorizes Western culture as a discursive cultural category that organizational members call upon to navigate through and realign frame disputes. Building on the discussion above, several theoretical implications can be suggested. First, binary cultural categories can be understood as discursive tools that are applied in globally distributed organizations to sustain working relationships and to maintain convenient and non-confrontational definitions of problematic situations. Categories such as 'Western culture' and 'Eastern culture' provide a broad framework within which members can rationalize a range of behaviours. Thus, these over-arching cultural categories serve as a psychologically safe shield from behind which members can address and attempt to realign frame disputes. This is of course not to suggest that cross-cultural IS studies where culture is assumed to be a cognitive variable are flawed. Indeed, cross-cultural differences have an important bearing on collaborative work in globally distributed organizations (see Avison \& Banks, 2008). However, it is important to recognize that alongside their applicability as a lens, broad cultural categories also appear to have a life of their own in global organizations as discursive resources (Cohen \& El-Sawad, 2007). Second, actors are fully complicit in reproducing the idea of Western culture as a binary opposite of their own Eastern or Indian culture. The arguments about the individualistic, instrumental, materialistic, intolerant and socialist nature of Western culture helped members' reconcile the OFD thereby recreating the idea of vast cultural differences between the West and the East. Thus, stereotypical notions of Western culture can be seen as a self-reproducing machine, which provides discursive material to manage framing differences. Therefore, it may not be very meaningful to talk about 'Western culture’ as an ontological reality (see Ozkazanac-Pan, 2010). 
Third, the exploration of cultural discourses cannot be divorced from the broader aspects of status and power asymmetries underpinning IT offshoring relationships. Crosscultural IS research on the West and the East tends to exclude the impact of forces and variables beyond the particular cultural practices and processes of focus. This study suggests that actors' mobilization and interpretation of cultural notions reflexively take into account the larger contours of status and power hierarchies within globally distributed organizations (see Ravishankar et al., 2012). Fourth, as seen in the invoking of contradictory discourses, members do not always aim for consistent cultural interpretations. As long as the interpretations help achieve realignment of frame disputes, they appear unperturbed by the idea of contradicting themselves during their invoking of cultural themes. This inevitably raises questions about the ability of cross-cultural IS research to identify enduring cultural attributes of organizational groups. Fifth, this study contributes to the burgeoning literature that views culture as a set of resources individuals draw on (see Swidler, 1986; Leonardi, 2011). In particular, the study suggests that amongst the vast array of cultural resources which offshore organizational members have at their disposal, the discursive mobilization of beliefs about Western culture is particularly relevant for realigning OFD. Finally, the persistent and recursive adoption of discourses about Western culture may result in the emergence of an organizational culture with a shared set of stereotypical assumptions about Western counterparts. When OFD arise, members of such a culture may be less inclined to consider other explanations given their tendency to habitually invoke 'cultural' ones.

\section{Practical implications}

It is possible that in many IT offshoring organizations, categories such as 'Western culture' are employed as all-weather arguments to manoeuvre around difficult situations. In the long term, however, this can seriously harm the cognitive capability of managers to develop cross-cultural sensibilities and to identify areas where cultural differences are in fact most likely to affect relationships with the collaborating onshore (or offshore) partner. Practitioners might find this paper useful in re-examining their beliefs about Western (and Eastern or Indian) culture. In particular, the paper can help mangers to distinguish between instances of discursive use of cultural arguments and instances where cultural differences actually affect every day work. Of course, managers may find that there are overlaps. That is, a given situation may involve both cross-cultural differences and their discursive deployment by members. This should not come as a surprise given that the use of culture as a lens in 
research is inextricably linked to the lay use of the term by organizational members (see Watson, 2002). However, the point here is that being able to make this analytical distinction will almost certainly help managers to work confidently towards reducing incompatibilities with a geographically distant collaborator. Cross-cultural training programmes are now a routine activity in many globally distributed organizations. This paper can assist managers who run such programmes to develop a better understanding of the myriad creative ways in which software development teams can use the idea of culture to solve OFD as and when they crop up. The findings of this paper can stimulate this group of practitioners to design programmes that go beyond offering a laundry list of cultural differences between the West and the East. The paper can also educate new employees about how the notion of crosscultural differences can be deployed to manage conflicting situations during collaborative projects, especially when power differentials are high.

\section{Discursive mobilization of 'culture' for OFD realignment: The other side of the story}

While the process model developed in this paper showcases the discursive mobilization of arguments about Western and Eastern culture as one good way of stabilizing and maintaining offshore-onshore relationships, such an approach could have its negative sides as well. In the long run, the use of such arguments to accomplish cognitive realignments can actually hinder collaboration and create dysfunctional relationships. The socialpsychological process of achieving OFD realignment described here is by no means a fully rational and systematic approach to resolving differences. The modus operandi of the SUB members is reminiscent of what Argyris (1986, p.75) called 'defensive routines'. Instead of

methodically exploring other possible underlying reasons for the OFD (e.g., things that they may have done to trigger the OFD), SUB members routinely pounced on 'cultural' explanations to make sense of the conflicts and to defend themselves. No doubt, this helped them to maintain a self-esteem enhancing definition of situations (see Goffman, 1959) and to keep their self-respect intact, particularly in light of the glaring power differential with HQ. But on the other hand such a strategy could have also stopped them from discovering areas of real differences (cultural or otherwise) with HQ and from trying to resolve them in an open and transparent manner. Thus, as collaborative onshore-offshore projects get increasingly tasked with the management of complex and innovative operations, collective mental reconciliations of the kind evident in this case also carry the risk of perpetuating cultural stereotypes, restricting learning opportunities, creating unhealthy working environments and paralyzing relationships between offshore and onshore teams. 
Managers therefore need to bear in mind that 'cultural' discourses-driven cognitive reorganizations and mental reconciliations need not always be the best available strategy for dealing with OFD. In both onshore and offshore units, managers could encourage (and not take offense to) the unlearning of face saving and habitual defensive responses (see Argyris, 1986, 1990). Managers can also provide organizational members with a different kind of psychological safety (see Schein, 2009; Edmondson, 2012) than what is available through stereotypical 'cultural' arguments. For example, managers can defuse the anxieties associated with situations of disputes and conflicts by reframing them as good opportunities (a) for objective exploration and continuous learning and (b) for honestly reflecting on the shortcomings of both offshore and onshore participants (see Edmondson, 2012; Friedman and Arieli, 2011). By engaging in such a process of positive reframing it may be possible to strengthen the underlying structure of the relationship (Smith, 2011) and help both offshore and onshore members to interact more fruitfully. Members on both sides may also find it useful to 'negotiate the reality' of conflicts and disputes through frank conversations with each other, preferably in informal and relaxed settings (see Friedman and Arieli, 2011). These conversation sessions may lead both sides to open up, and to inquire in greater detail and humility into their own and into the other side's cultural values and predispositions. Such a process clearly enhances the prospects of a less suspicious and a more rewarding offshoreonshore collaborative IT work.

\section{Limitations and Future Research}

The different types of OFD are essentially frame disputes between two sides. But in this ethnographic inquiry, I relied solely on SUB members to present both sides of the OFD. In other words, I have focused squarely on the Indian side of the collaborative equation. While this is consistent with ethnographic principles, which suggest the generation of indepth insights through intensive fieldwork in a particular research setting, future work also needs to explore OFD from the point of view of onshore organizational members in order to complement the findings of this study. Further, given that this paper relates to an intensive, but single-site ethnography caution must be exercised in generalizing the findings to other globally distributed organizational environments. More empirical work is required to better understand the use of a culture as a discursive resource in different types of IT offshoring organizations. For instance, it would be interesting to examine the cultural arguments invoked in a subsidiary unit dealing with American rather than European counterparts. Similarly, 
research could also explore the application of culture as a discursive resource within Indian (or Eastern) headquartered vendor organizations. Also, given the movement towards universally recognizable corporate cultures, it would be fruitful to investigate the dynamic interplay between discursive deployment of cultural arguments and the practices that contribute to a strong corporate culture in globally distributed organizations. It is not unreasonable to expect that as members in such organizations get reined in by strong corporate cultures, the intensity of OFD could reduce significantly even though arguments about 'West-East' cultural differences may continue to persist in everyday organizational discourse. Lastly, in this paper I have considered only one broad category of arguments (i.e. 'cultural') employed by offshore members to realign OFD. This particular focus should not blind scholars to other mechanisms likely to be used both by offshore and onshore members to manage OFD.

\section{Concluding remarks}

Despite the emergence and rapid growth of globally distributed organizations, there are important gaps in our understanding of how members in such cross-cultural settings accomplish collaborative IT work (Hinds et al., 2011). This study explores and illustrates how members in offshore locations discursively employ a range of 'cultural' beliefs and interpretations as resources to realign OFD. In formulating OFD as a phenomenon of interest in IT offshoring settings, I drew on and extended Goffman's (1974) notion of frame disputes. The findings suggest that ideas about categories such as Western culture are not only useful as analytical devices for scholars, but also have immense discursive everyday value for organizational members to reconcile and realign different types of OFD. The sociopsychological process model developed in the paper helps understand how extended 'cultural' frameworks and cognitive reinterpretations play an influential role in the effective management of offshore-onshore relationships.

\section{Acknowledgements}

I am grateful to the three anonymous reviewers and the associate editor for their insightful and constructive comments.

\section{References}


AILON-SOUDAY G and KUNDA G (2003) The local selves of global workers: the social construction of national identity in the face of organizational globalization. Organization Studies 24(7), 1073-1096.

ARGYRIS C (1986) Skilled incompetence. Harvard Business Review 64(5), 74-79.

ARGYRIS C (1990) Overcoming Organizational Defenses: Facilitating Organizational Learning. Allyn and Bacon, Boston.

ATKINSON P and HAMMERSLEY M (2007) Ethnography: Principles in Practice (3rd edn). Routledge, New York.

AVISON D and BANKS P (2008) Cross-cultural (mis)communication in IS offshoring: understanding through conversation analysis. Journal of Information Technology 23(4), 249268.

AZAD B and FARAJ S (2011) Social power and information technology implementation: a contentious framing lens. Information Systems Journal 21(1), 33-61.

BARRETT M and OBORN E (2010) Boundary object use in cross-cultural software development teams. Human Relations 63(8), 1199-1221.

BARINAGA E (2007) 'Cultural diversity' at work: 'national culture' as a discourse organizing an international project group. Human Relations 60(2), 315-340.

BENFORD RD (1993) Frame disputes within the nuclear disarmament movement. Social Forces 71(3), 677-701.

BENFORD RD and SNOW DA (2000) Framing processes and social movements: an overview and assessment. Annual Review of Sociology 26(1), 611-639.

CHREIM S (2006) Managerial frames and institutional discourses of change: employee appropriation and resistance. Organization Studies 27(9), 1261-1287.

COHEN L and EL-SAWAD A (2007) Lived experiences of offshoring: an examination of UK and Indian financial service employees' accounts of themselves and one another. Human Relations 60(8), 1235-1262.

DAVIDSON E (2006) A technological frames perspective on information technology and organizational change. Journal of Applied Behavioral Science 42(1), 23-39.

DIBBERN J, WINKLER J and HEINZL A (2008) Explaining variations in client extra costs between software projects offshored to India. MIS Quarterly 32(2), 333-366.

DUSTDAR S and HOFSTEDE GJ (1999) Videoconferencing across cultures - a conceptual framework for floor control issues. Journal of Information Technology 14(2), 161-169.

EDMONDSON A (2012) Teaming. Jossey Bass, San Francisco. 
FANG X, BENAMATI J and LEDERER AL (2011) Coping with rapid information technology change in different national cultures. European Journal of Information Systems 20(5), 560-573.

FRENKEL M (2008) The multinational corporation as a third space: rethinking international management discourse on knowledge transfer through Homi Bhabha. Academy of Management Review 33(4), 924-942.

FRIEDMAN V and ARIELI D (2011) Building partnerships across cultures as negotiating reality. In The Paradox in Partnership: The Role of Conflict in Partnership Building (DESIVILYA HS and PALGI M, Eds), pp. 79-92, Bentham Ebooks.

GOFFMAN E (1959) The Presentation of Self in Everyday Life. Anchor Books, New York.

GOFFMAN E (1974) Frame analysis: An Essay on the Organization of Experience. Harper and Row, New York.

HAYEK, FA (1944) The Road to Serfdom. Routledge Press, UK.

HINDS P, LIU L and LYON J (2011) Putting the global in global work: an intercultural lens on the practice of cross-national collaboration. Academy of Management Annals 5(1), 135188.

HSU CW (2009) Frame misalignment: interpreting the implementation of information systems security certification in an organization. European Journal of Information Systems 18(2), 140-150.

JAIN RP, SIMON JC and POSTON RS (2011) Mitigating vendor silence in offshore outsourcing: an empirical investigation. Journal of Management Information Systems 27(4), 261-298.

KEIL M, IM GP and MÄHRING M (2007) Reporting bad news on software projects: the effects of culturally constituted views of face-saving. Information Systems Journal 17(1), 5987.

LANE RE (2000) The Loss of Happiness in Market Democracies. Yale University Press, New Haven.

LEONARDI PM (2011) Innovation blindness: culture, frames, and cross-boundary problem construction in the development of new technology concepts. Organization Science 22(2), 347-369.

LIN A and SILVA L (2005) The social and political construction of technological frames. European Journal of Information Systems 14(1), 49-59.

LIPSET SM (1996) American Exceptionalism: The Double-Edged Sword. Norton, New York. 
MATTARELLI E, BERTOLOTTI F and MACRI DM (2013) The use of ethnography and grounded theory in the development of a management information system. European Journal of Information Systems 22(1), 26-44.

MCCOY S, GALLETTA DF and KING WR (2007) Applying TAM across cultures: the need for caution. European Journal of Information Systems 16(1), 81-90.

METIU A (2006) Owning the code: status closure in distributed groups. Organization Science 17(4), 418-435.

NICHOLSON B and SAHAY S (2001) Some political and cultural issues in the globalisation of software development: case experience from Britain and India. Information and Organization 11(1), 25-43.

ORLIKOWSKI WJ (1992) The duality of technology: rethinking the concept of technology in organizations. Organization Science 3(3), 398-427.

ORLIKOWSKI WJ and GASH DC (1994) Technological frames: making sense of information technology in organizations. ACM Transactions on Information Systems 12(2), 174-207.

ORLIKOWSKI WJ (2000) Using technology and constituting structures: a practice lens for studying technology in organizations. Organization Science 11(4), 404-428.

ÖZKAZANÇ-PAN B (2008) International management research meets "the rest of the world". Academy of Management Review 33(4), 964-974.

PRATT MG, ROCKMANN KW and KAUFMANN JB (2006) Constructing professional identity: the work of role and identity learning cycles in the customization of identity among medical residents. Academy of Management Journal 49(2), 235-262.

RAVISHANKAR MN, COHEN L and EL-SAWAD E (2010) Examining resistance, accommodation and the pursuit of aspiration in the Indian IT-BPO space: reflections on two case studies. Industrial Relations Journal 41(2), 154-167.

RAVISHANKAR MN, PAN SL and LEIDNER DE (2011) Examining the strategic alignment and implementation success of a KMS: a subculture-based multilevel analysis. Information Systems Research 22(1), 39-59.

RAVISHANKAR MN, PAN SL and MYERS MD (2012) Information technology offshoring in India: a postcolonial perspective. European Journal of Information Systems 22(4), 387402.

SARKER S and SARKER S (2009) Exploring agility in distributed information systems development teams: an interpretive study in an offshoring context. Information Systems Research 20(3), 440-461.

SCHEIN E (2009) The Corporate Culture Survival Guide. Jossey-Bass, San Francisco. 
SHARROCK W and RANDALL D (2004) Ethnography, ethnomethodology and the problem of generalisation in design. European Journal of Information Systems 13(3), 186-194.

SMITH DM (2011) The Elephant in the Room. Jossey-Bass, San Francisco.

SNOW DA, ROCHFORD JR EB, WORDEN SK and BENFORD RD (1986) Frame alignment processes, micromobilization, and movement participation. American Sociological Review 51(4), 464-481.

STRAUSS A and CORBIN J (1998) Basics of Qualitative Research: Techniques and Procedures for Developing Grounded Theory. Sage, Thousand Oaks, CA.

SWIDLER A (1986) Culture in action: symbols and strategies. American Sociological Review 51(2), 273-286.

VAN MAANEN J (1979) The fact of fiction in organizational ethnography. Administrative Science Quarterly 24(4), 539-550.

VEIGA JF, FLOYD S and DECHANT K (2001) Towards modelling the effects of national culture on IT implementation and acceptance. Journal of Information Technology 16(3), 145158.

WALSHAM G (2002) Cross-cultural software production and use: a structurational analysis. MIS Quarterly 26(4), 359-380.

WATSON T (1994) In Search of Management. Routledge, London.

WATSON T (2002) Professions and professionalism: should we jump off the bandwagon, better to study where it is going? International Studies of Management \& Organization 32(2), 93-105.

WATSON TJ (2011) Ethnography, reality, and truth: the vital need for studies of 'how things work' in organizations and management. Journal of Management Studies 48(1), 202-217.

ZIMMERMANN A and RAVISHANKAR MN (2011) Collaborative IT offshoring relationships and professional role identities: reflections from a field study. Journal of Vocational Behaviour 78(3), 351-360. 